\title{
ERRATUM
}

Hans Van Os • Piet Stam • Richard G. F. Visser

Herman J. Van Eck

\section{RECORD: a novel method for ordering loci on a genetic linkage map}

Published online: 29 November 2005

(C) Springer-Verlag 2005

\section{Theor Appl Genet (2005) 112:30-40}

The formula following Eq. 2 in the subsection "A yardstick of performance" was rendered incorrectly, in that no space was left between the formula and the parenthetical remark that followed. It should have appeared as shown here.

$r_{s}=1-\sum_{i=1}^{m} 2 p_{i}^{3}, \quad \tau=1-\sum_{i=1}^{m} 2 p_{i}^{2} \quad\left(\sum p_{i} \leq 1\right)$. dx.doi.org/10.007/s00122-005-0097-x

H. V. Os · P. Stam · R. G. F. Visser · H. J. V. Eck (ه) Laboratory of Plant Breeding, Wageningen University,

386, 6700 Wageningen, AJ, The Netherlands

E-mail: herman.vaneck@wur.nl

Tel.: + 31-317-482837

Fax: + 31-317-483457 